INTERNATIONAL DESIGN CONFERENCE - DESIGN 2018

https://doi.org/10.21278/idc.2018.0257

\title{
FACILITATING NEED FINDING AND PROBLEM FORMULATION DURING COOPERATIVE WORK TERMS THROUGH VIRTUAL INSTRUCTION - PILOT IMPLEMENTATION RESULTS
}

\author{
O. Nespoli, A. Hurst and J. Russell
}

\begin{abstract}
This project aimed to teach, facilitate the learning of, and assess need finding and problem formulation skills while students were immersed in an authentic practice environment during their coop work terms. An interdisciplinary team of students was placed in a manufacturing facility where they were asked to need find and propose significant problems to solve while they were taught design methods remotely. Students reported that they learned more deeply than a classroom environment because they were able to be in constant engagement with the problems they were trying to solve.
\end{abstract}

Keywords: problem solving, design education, design practice

\section{Introduction}

"Necessity is the mother of invention" - Plato

"The mere formulation of a problem is far more essential than its solution" - Albert Einstein and Leopold Infeld

As engineering educators, we remain continually challenged to better prepare our students for the demands of current day professional practice. The problems that are encountered there are not welldefined; "they tend not to present themselves to practitioners as problems at all but as messy, indeterminate situations" (Schon, 1987, p. 4).

Henderson (1998) provides a useful view of knowledge that can inform this challenge, elegantly presenting the Epistemology space (E-space), as shown in Figure 1. We recognize that the modern research university is underpinned by an epistemology based on technical rationality, primarily in teaching and assessing coded technical and scientific knowledge (top two quadrants). This is not representative of authentic professional practice, central to which is addressing complexity, uncertainty and indeterminacy - safely, effectively and efficiently. Addressing these important 'zones of practice' requires a special kind of knowledge - knowledge that is difficult to teach as it is uncoded and embedded in practice (lower two quadrants). This knowledge is gained by expert practitioners as a result of 'enskilment' that comes from being actively engaged with a practice environment, and not by internalizing a stock of knowledge in a mechanistic way (Henderson, 1998).

This key skill - engaging with the practice environment, or what Schon (1987) terms reflective practice - is best exemplified in design, considered the most important cognitive (as well as affective and conative) activity in everyday professional engineering contexts (Jonassen, 2000). The designer conducts a 'reflective conversation' with the situation, generating design 'moves' to shape the situation (Schon, 1987). Unfortunately, a disjunction of contexts exists between doing authentic design (in 
practice contexts) and teaching design (in academic contexts) (Bucciarelli, 2003). In particular, most design problems that are currently addressed by engineering students during their academic terms are broadly-defined or well-defined (as opposed to not-defined or ill-defined), only requiring the application of coded technical and scientific knowledge.

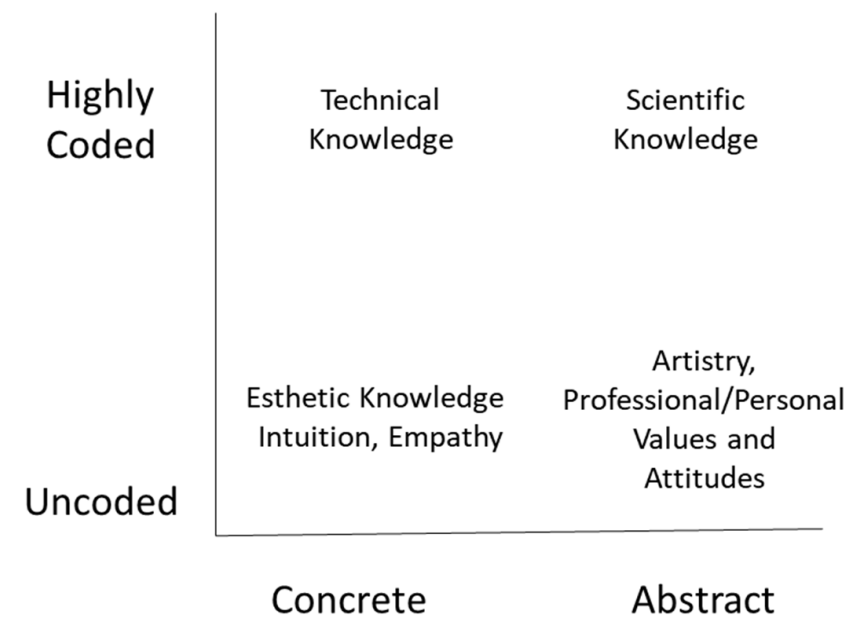

Figure 1. Types of knowledge in the E-space, adapted from Henderson (1998)

The skills and behaviours of reflective practice should be explicitly taught, but where and how?

The medical profession deals with this challenge through clinical teaching residencies in authentic contexts. Clinicians teach, by example, a number of residents as they go about the daily authentic professional life of a medical practitioner.

The opportunity to teach, learn and assess need finding and problem formulation, remains largely unavailable for engineering students to learn and for instructors to teach and assess during academic terms. The context of professional engineering practice is required in order to learn these important design skills. Fortunately, this context is available in the "clinical" dimension of academic programs during industrial internships.

At the University of Waterloo, co-operative work terms (also known as "co-op terms", or "co-op"), which are four-month industry-based internships, are the distinguishing feature of engineering programs. They represent latent, underdeveloped and potentially significant opportunities for clinical instruction of engineering design thinking (Christensen and Eyring, 2011). They can facilitate the learning of uncoded knowledge and the behaviours around engaging effectively and appropriately with authentic practice problems and situations. However, given the typical geographical dispersion of coop placements, it is not feasible for engineering instructors ('clinicians') to be together in the workplace ('hospital') with all engineering students ('residents'). Advances in, and improved affordability of, communication technology (e.g., video conferencing) have enabled the possibility of clinical instruction at a distance. Suddenly, virtual clinical instruction seems possible.

\section{2. iCapstone academic programming}

"iCapstone" is new academic programming that is intended to be a unique industry-funded fellowship program available to selected and qualified students enrolled in the interdisciplinary engineering capstone design series of courses (Nespoli and Russell, 2016). As illustrated in Figure 2, the iCapstone initiative will connect the academic term (3B) preceding the final co-op term with the final interdisciplinary capstone design course sequence, which students take in their two senior year terms (4A and 4B). 


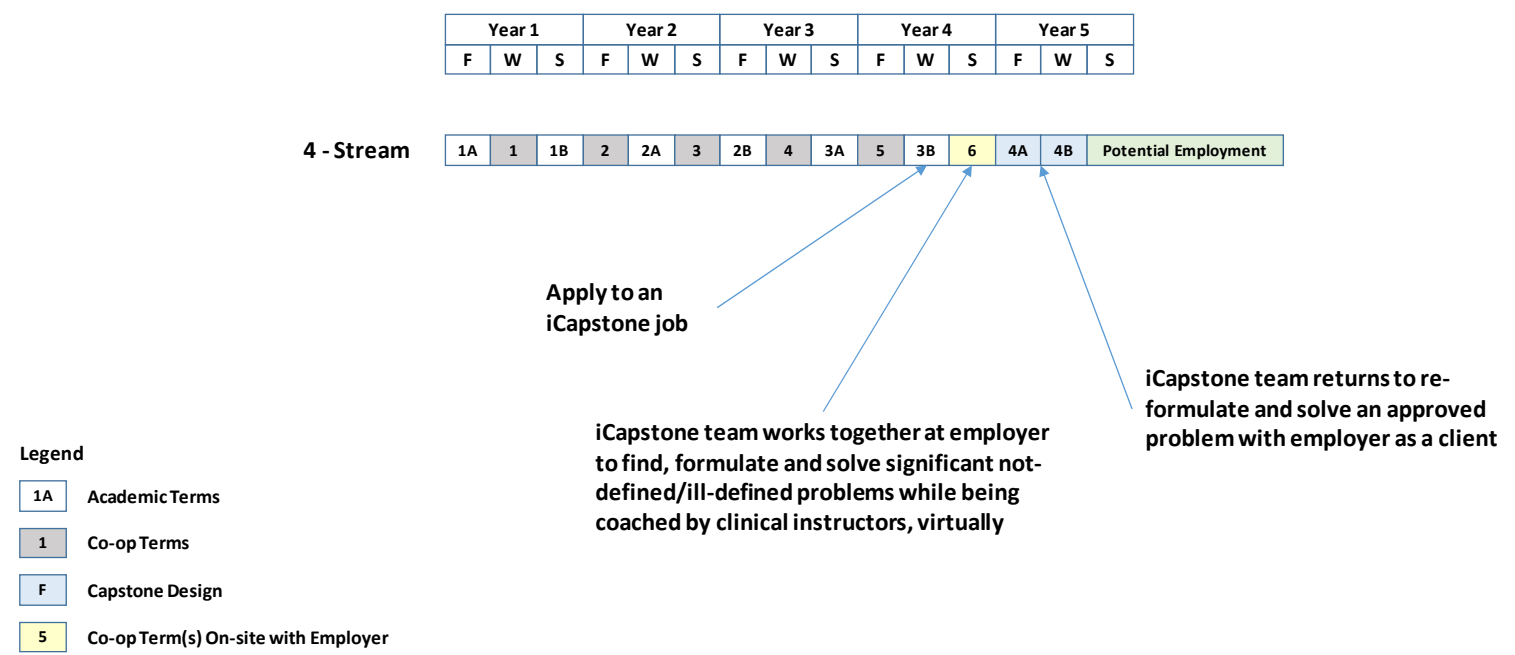

Figure 2. iCapstone pilot programming

The new programming aims to teach, facilitate the learning of, and assess need finding and formulation skills while students are immersed in professional engineering practice contexts during their co-op terms, and while the instructors teach them remotely. Students find, formulate and propose tough and relevant problems sourced during their co-op terms, and bring those 'broadly-defined' complex problems into the capstone design courses for reformulation, solving, verifying and implementing, while engaging researchers who have specialized knowledge as Faculty Advisors.

We use Schon's theory of reflective practice, specifically reflection-in-action and reflection-on-action, to facilitate the development of these design skills in our students. It is hypothesized that these authentic contexts, coupled with (virtual) clinical instruction based on Schon's theory, will facilitate deep learning of the reflective practice of need finding and problem formulation skills.

The intended outcome of the overarching research project is to assess the effectiveness of teaching, learning and assessing need finding and problem formulation for undergraduate engineering students immersed in an authentic engineering work context.

The research questions we aim to investigate for the overall project are:

- To what extent can need finding and problem formulation be taught, learned and assessed during a cooperative work term?

- How can clinical instruction, through the application of Schon's theory of reflective practice (1987), facilitate this?

These are rather ambitious questions that are not yet fully addressed. In this paper, we report on a pilot implementation of the iCapstone program and some preliminary findings with respect to exploring and experimenting with this new approach. The goal of the pilot was to demonstrate the feasibility of this new approach to learning, with respect to teaching students virtually in a remote clinical setting. These findings have already been used to inform a second pilot delivery, which is currently in progress.

\section{Pilot planning and implementation}

\subsection{Identification of industry partner and student selection}

The first step in developing the iCapstone pilot delivery was securing a suitable industry partner. Typically, when students are hired on a co-op term, the hiring organization has specific projects, tasks, and duties planned for the students to complete. Often, these are formalized in the job description and discussed during the co-op interview. It is often the case that students are hired to work on specific projects during their co-op terms, thus 'short-circuiting' the opportunity to need find and formulate problems on their own. In this case, it was important that the industrial partner agree that the students act as consultants, in other words, not be given defined problems to undertake, but empowered to find, formulate and propose these opportunities on their own. 
Our lead partner - Bata Innovation Lab (hereon referred to as Bata), a contact of the lead author - was approached to hire an interdisciplinary team of co-op students to be placed in an opportunity-rich international engineering context. From its perspective, Bata sought to introduce disruptive and innovative thinking to a Bata manufacturing company that had remained largely unchanged and static for many years. The pilot would hopefully identify areas where Bata could modernize the manufacturing process by making it more efficient while reducing costs. Bata Colombia was selected as the location for the pilot since the management team there were looking at new innovative approaches in manufacturing and willing to make the investments necessary to support the project. This was helpful from a logistical perspective as Bata Colombia is also relatively close to Canada for travel, which was a benefit for the students and the company.

Bata advertised and held information sessions to promote this co-op opportunity to potential students. The lead instructor (and lead author on this paper) was asked to participate in the hiring process. During the interviews, all of the students were asked whether they could identify specific methods for need finding. Only a small percentage could identify explicitly even one of the four main discovery skills normally used (questioning, observation, talking to people, experimenting yourself) (Dyer et al., 2011). Three engineering students were ultimately hired, forming an interdisciplinary team of two mechanical engineering students and one management engineering student. Of the three, only one was fluent in Spanish. Instructors met with the students prior to their departure and provided some background information on the research program, and the intended project and learning outcomes. There was only brief instruction provided on the design methodologies planned.

\subsection{Pilot implementation}

In May 2017, the students began their international co-op placement. The lead instructor accompanied the students to Colombia and attended the first week of the three week orientation program planned for the students. The goal of this orientation was for students to learn about the commercial and operational parts of the business at Bata Colombia. This was very useful for the instructor since he was able to tour the facility, meet the executive management team, and other managers. He presented a proposed instructional plan for the co-op term that consisted of weekly project review meetings at the start of each week and weekly learning reflection meetings at the end of each week. All meetings would be conducted remotely between the co-op students in Colombia and the two instructors in Canada. The learning sessions at the end of the week were to be video and audio recorded for future analysis. According to the plan, students were not to be given much task definition by Bata Colombia on what they were expected to accomplish. Instead, they were expected to undertake an intensive need finding, and required to deliver a continuously-updated needs list, an implemented design solution based on one or more of the identified needs, and work term reports in the form of case studies by the end of the 17-week term. The pilot's schedule with deliverables is shown in Figure 3.

As they immersed themselves in the plant's operations, the students had a very intensive learning period on how a factory is managed, and on the processes and the various technologies involved. They quickly grasped the internal workings of a Bata shoe factory and the problems and limitations involved, in spite of having no prior shoe manufacturing experience. They were also able to draw their own conclusions on many key areas of the manufacturing process that required improvement. The interactive sessions with the factory managers gave them a better understanding of the intricacies of running a shoe factory in Colombia.

The iCapstone pilot was unique in that students received real-time engineering design methods instruction while immersed in the context of the host organization. The main intended learning outcome was to "identify, represent/formulate and communicate an engineering problem/opportunity". The teaching and learning methods used during the learning sessions consisted of structured and unstructured/unplanned/opportunistic elements.

The structured elements consisted of formal presentation by the lead instructor of design methods (some weeks) and having students reflect on their week engaging with their problems (every week). Schon's theory of reflective practice was used here in a very practical way - students were each asked to reflect on what about their problem that unfolded was expected, and what was not expected. 
The non-structured (i.e., opportunistic) element of the teaching occurred as learning sessions unfolded organically. Depending on the student responses to the instructors' questions, students would be occasionally offered a design method, tool, or approach that would help address the problem formulation and solving process. This included constructing a succinct and functionally accurate need statement, performing a functional analysis by identifying functional, non-functional and constraint requirements, generating function structures or the products and process of concern, using a "9-screen" vision tool (Buhkman, 2012) to include system level process and organizational elements of the problem, identifying contradictions, constructing verb-noun pairs for functions, etc.

Overall, instructors sought to receive an update on the students' progress, become aware of their challenges, and provide expert advice and recommendations. Therefore, these virtual learning sessions were not unlike design review meetings that students participate in during regular capstone design courses on their academic term.

Throughout the term, students delivered a needs list with 204 identified needs, and based on one of those needs, were successful in developing a solution in the form of a medium fidelity prototype that underwent initial testing on the production line. Their analyses verified that their proposed solution had the potential to meet increased production capacity goals while meeting economic feasibility targets. At the end of the co-op term, the solution was transitioned to an implementation team to complete. Additionally, the students delivered two case studies as part of the academic requirement for a work term report. Both capture the problems identified and show evidence of the use of design methods taught by the instructors throughout the co-op term.

From Bata's perspective, the project delivered more than 200 potential improvements ideas. The proposed design had a projected $20 \%$ efficiency increase with a Return on Investment (ROI) of 3 years. The selection of students, pre-project briefing, the assignment of a focus team to guide them and weekly monitoring and alignment of objectives between Canada and Colombia was one of the reasons the project goals and expectations were met.

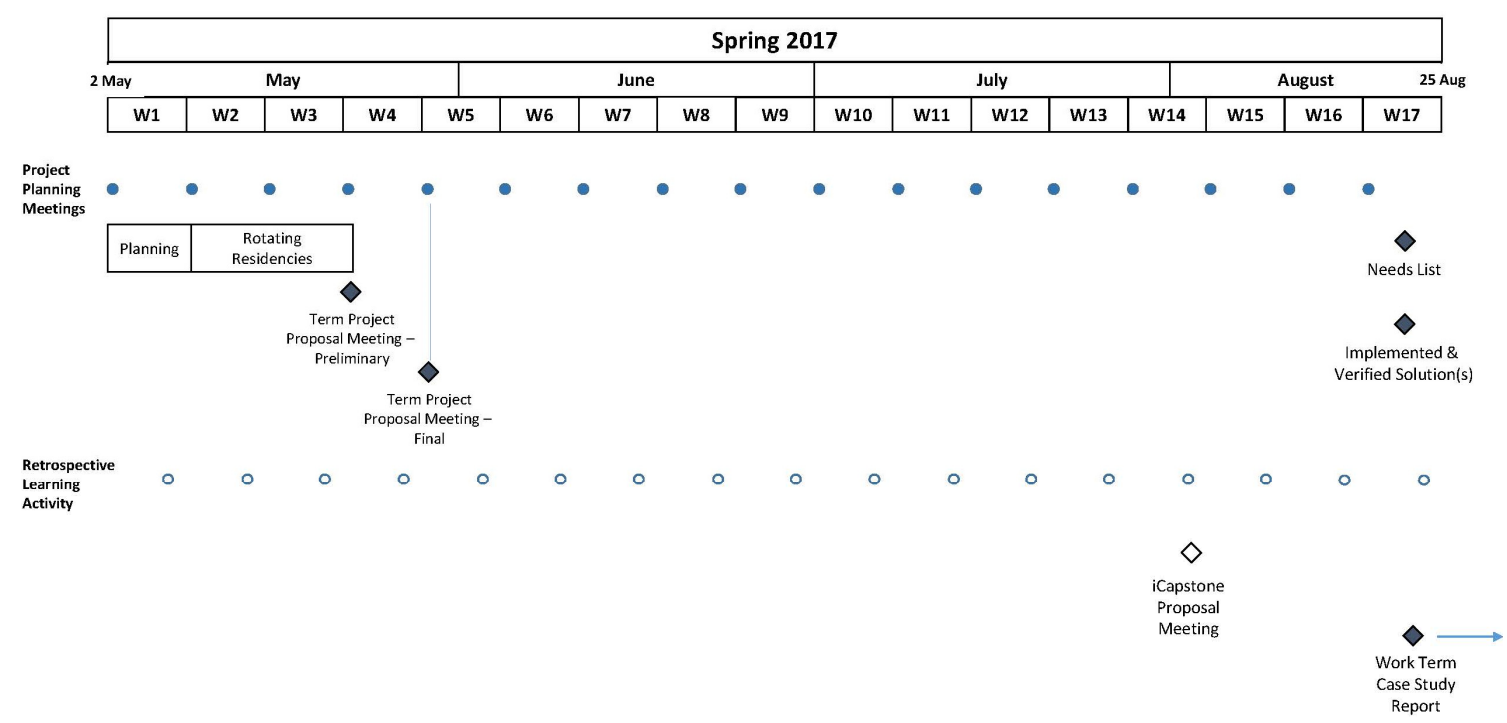

Figure 3. iCapstone pilot schedule and deliverables

While students received significant instruction in engineering design methods while on the iCapstone work term, they did not receive any official course credit for it, other than the regular co-op credit (students must receive five such credits before graduation). Upon return to the university, they enrolled in the regular capstone design course, as per their program calendar. While the intention was that they bring a problem that they found from their co-op employer into the capstone design course, they instead chose to bring a problem that they found outside of their work while in Colombia, and to undertake an entrepreneurial venture. This was unexpected, but nevertheless still lies within the intent and spirit of the new programming. 
Students submitted case studies of two of the problems they undertook, as part of their requirement to submit a work term report (all students in engineering are required to do so). A rubric developed for need analysis was used to assess the case studies submitted (refer to the Appendix). The assessment of the submitted case studies found that students used need analysis methods with which they became familiar during the virtual learning sessions. This demonstrates that this is a feasible assessment methodology for future implementations.

\section{Student feedback}

Feedback from the three students that participated in the pilot was sought and collected upon their return to Canada.

First, participants completed an individual survey, composed of a number of short-answer questions on their experience and perceptions of the effectiveness of the pilot. The questions prompted student feedback on aspects of the pilot were believed to be significantly different from co-op terms in which engineering students typically participate, namely:

1. The absence of a predefined project for students to work on during their co-op term ("Describe what you liked/disliked about not having a pre-defined project to undertake at the start of the coop term")

2. The freedom to act under limited supervision ("Describe what you liked/disliked about not having a direct supervisor to report to during your co-op term (i.e., you were asked to act as consultants)")

3. The effectiveness of the technology that facilitated the virtual interaction with the instructors ("Describe what you liked/disliked about the technology available for learning remotely")

4. The addition of engineering design methods instruction during the co-op term ("Describe what you liked/disliked about 'taking' a capstone 'course' during your work term")

5. The possibility of a future formal integration of a regular capstone design course with a co-op term ("Would you like/dislike taking your first capstone course during your co-op term instead of on your academic term?")

Survey answers were collected and analysed, and main themes were identified.

The second component of the feedback collection was a focus group with all three participants, facilitated by a research assistant. The guided discussion built on the main themes that emerged from the individual surveys, with the facilitator seeking clarification and further elaboration on the students' answers. The focus group discussion was audio-recorded and later transcribed.

All three students completed the individual survey as well as participated in the focus group discussion. Below we summarize the main findings that emerged.

\subsection{Project definition}

All three participating students identified significant advantages to being entrusted with selecting their own projects. First, they noted that the freedom to search for and select a project area allowed them to identify "actual issues" in production and thus target an area of "real need" in the organization. Second, they enjoyed the autonomy and responsibility that came with the freedom to choose their own project. This process was itself a source of learning that provided them with hands-on training on how to systematically identify problems. Third, they were able to choose project topics that were suitable to their own technical and professional development interests. The students noted that they were able to use their "engineering judgement" to choose project areas in which their specific skills could be best applied. All of the above factors contributed to an increased level of engagement with the project.

However, the process of choosing suitable projects was not without difficulties. Students noted that management had its own view on what areas of the company deserved attention and was at times resistant to the students' proposals. From the students' perspective, the entire process - from observing various areas of the company, to identifying target areas for improvement, to securing management buyin - was surprisingly very time-consuming. Nevertheless, while challenging, the process of persuading management was in itself a valuable learning opportunity. As one of the students put it: “...while I didn't enjoy it, it definitely taught me some of the skills needed to succeed when dealing with management." 
In the individual surveys, the students explained that one undesirable consequence of the lengthy need finding process was that they were not able to take part in the full implementation of the solution that they designed. This aspect was disappointing for the students, who worried that there would be a lot of knowledge lost in the hand-off to the implementation team. In the focus group discussion, they clarified that this experience was not necessarily unique to this pilot, but rather a common occurrence in other co-op terms they had experienced, where "endless projects... pass from one co-op [student] to the next." The students also clarified that they did not regret taking the time to carefully identify and examine different needs before proposing project areas to management. Rather, they believed that it was the time they spent getting to know the operations of other departments (e.g., finance) at the beginning of the term, that delayed their need finding in production. Nevertheless, all three students stated that they would not have preferred a longer (e.g., 8-month) co-op term, even if that would have meant an opportunity to complete the implementation of their solution.

\subsection{Supervision}

Another aspect of this pilot that was very different from the typical co-op term was the intentional limiting of direct supervision on the students. Co-op students are usually assigned to a particular department within the host organization and report to one (or, in the rare case, more) specific supervisors. In this iCapstone pilot however, students were in an unusual arrangement, in which they were interviewed and selected by Bata's head office in Canada (in conjunction with one of the instructors) and then assigned to the Colombian branch to act as "external consultants". There they worked with (not for) three different departments: Production, Cost and Efficiency, and Maintenance. From the perspective of Bata Colombia, students were brought in from head office and were 'reporting' back to the company's head office and their instructors in Canada. Because local management believed that the students were being academically assessed by the instructors, they were reluctant to provide (critical) feedback to the students, fearing that this would negatively impact the students' grades. From the point of view of the instructors, however, the instructors' role was mostly to facilitate learning, and in some cases, to provide expert technical advice. In their feedback, students expressed that this misalignment of expectations from the two parties limited progress in their project somewhat.

Students saw these special circumstances as both positive and negative. On the positive side, they stated that they were able to take advantage of their status as a separate entity from the existing departments, allowing them to observe and evaluate various areas in the company (and thus not limit themselves to particular departments). Not reporting to a specific supervisor or department gave them the autonomy to ultimately decide for themselves which areas of the company to devote the remainder of the term on. This meant that they were able to make the kinds of decisions - about the project, tools, methods, and timeline - which, in a typical work term, would be made for them by a supervisor.

Existing outside of the formal company structure also impacted their relationship with the other workers. The students noted that they occupied a very unusual position at the company - neither typical interns (that would be relegated to basic tasks) nor management - which allowed them to get valuable information from the workers.

Not reporting to a specific local department and supervisor also presented some difficulties. The students described how the various departments each had their own goals and priorities, which made the project definition difficult. Each department would interpret the project goals differently, further limiting communication between the parties. The students suggested that in the future, once a project area is identified, a manager from that area should be assigned to supervise the students. It is important to have one dedicated point of contact to provide students with timely information, regular performance feedback, progress tracking, or adequate support and encouragement when needed.

\subsection{Virtual instruction}

While students at this institution participate in other virtual learning opportunities while on co-op (to fulfil professional development (PD) course requirements), the iCapstone pilot was significantly different in its delivery. All learning sessions with the instructors occurred over video conference. Students and instructors were also able to share screens to facilitate communication and feedback. In 
contrast, PD courses are typically delivered through short videos and offline assignments, with little to no interaction with faculty.

Students in the iCapstone pilot stated that they were already familiar with the technology and that it was easy to use. They really enjoyed the format of instruction, in particular the real-time face-to-face interaction with the instructors.

\subsection{Learning sessions}

Students seemed to view the learning sessions very positively. They stated that the covered content was "practical and useful" to what they were working on at the host organization. One student noted that because the instruction was tightly related to the work they were conducting, they gained "knowledge", rather than "facts". The student also stated that they found themselves applying the concepts "on a daily basis" and not just to the specific problems they were tackling at work. Finally, the formal instruction in engineering design concepts and methods provided them with the tools to define and formalize the identified problems at the host organization, which helped them to better explain them to management.

Students also stated that while participating in the learning sessions added to their weekly workload, they nevertheless looked forward to the sessions as an opportunity to reflect on their experience and engage in some higher-level thinking about their projects.

\subsection{Co-op and capstone design hybrid}

Should more students and host organizations become interested in the iCapstone "fellowship", there may be an opportunity to formally count the instructional component as the first capstone design course in the series of two (that students typically receive). This would not require any incremental faculty resources since one faculty member per team is usually assigned as an advisor during the capstone course during the academic term, and this faculty resource would simply be expended during the coop term instead of the academic term.

Students were asked about their opinion on this potential arrangement to take their first capstone course during the co-op term.

All three students provided very positive feedback on the experience of learning about design while immersed in the context of a real problem. They stated that compared to their classmates who were only learning about these concepts while on the academic term, they were having a much better learning experience in the course and were better prepared to tackle their design project. As one of the students put it, "we understand our limits better, have the ability to present our ideas in a clear manner, and are comfortable working in free form manner without a direct supervisor and faculty support." They noted that in their regular capstone course the instructor is limited to providing "general" instruction about engineering design to a large number of students, using case studies as a teaching tool. However, since all each student team works in a different design project topic, teaching through case studies, while valuable, is not as effective in providing project-specific instruction and guidance. Receiving that instruction while immersed in the problem context, "stuck so much better". One of the students further expanded on this point in the focus group discussion:

"I think you can learn more while you are in the "co-op environment" versus a "class environment". During the co-op term you can constantly and actively apply the learned concepts and techniques because the opportunities are right in front of you. While if you are learning these concepts in a class environment, you are no longer directly engaged with the problem, so I don't think the learning experience is as effective."

Students were not very enthusiastic about the idea of merging the first capstone course within a co-op term however. They stated that the reason they felt confident in using engineering design methods on their design project while on the academic term was precisely because they had already had an opportunity to practice working on a design project in the preceding co-op term. The co-op term integrated with design instruction was an effective means to achieve deep learning of engineering design methods; now students independently applied that learning in their capstone design project in their senior year: 
“...We're now reapplying all that learning we did and seeing how useful that is for a whole new project without being taught. I mean, we still go back and ask [the lead instructor] questions, but a lot of the time we're sitting there, we're reviewing the notes that he provided us with and we're seeing how does this affect our project, how can we use this."

While very enthusiastic about the model, students expressed concerns about its feasibility, especially in securing faculty resources to provide the intensive one-on-one instruction modelled by the iCapstone pilot. In the focus group, they discussed among themselves the possibility of turning some of the instructions into text and video documents, but all acknowledged that this would severely decrease the program's effectiveness.

\section{Study limitations and future research}

The effectiveness of this first implementation of the iCapstone program was largely evaluated through soliciting of feedback from the participating students (through individual surveys and a focus group) and through the reflections of the instructors and Bata representatives. This preliminary evaluation fulfilled the goals of the pilot implementation - demonstrating feasibility of this new programming. As a result, a second offering of this new programming was undertaken at a second international location with a different partner (a non-governmental organization (NGO)).

Throughout the Bata pilot, valuable data was collected including transcribed recordings of the learning sessions and written reflections and case studies produced by the students. The same dataset is also being collected in the second implementation. This data will be used to address the overarching research questions posed in Section 2. Potential frameworks for analysing the data that are being considered include design ontologies (e.g., using the FBS framework (Gero and Kannengiesser, 2004)), questionasking taxonomies (Eris, 2004; Cardoso et al., 2014; Hurst and Nespoli, 2018), and reflective learning models (Schon, 1987).

Students were intentionally placed in an opportunity rich and international location in order to present them with technical and non-technical opportunities. The cultural context was an important intentional element of this program that played an unexpectedly larger role in the students' learning experience. This was not specifically addressed and requires further evaluation.

\section{Conclusions and recommendations}

The iCapstone pilot at Bata Columbia was implemented to demonstrate the feasibility of teaching students engineering design, in particular need finding and formulation, remotely while students are in an authentic professional practice setting.

The pilot was successful in meeting these goals. Students were able to need find and formulate their own problems, when given the freedom to do so. They delivered a list of over 200 needs, proposed two impactful problems to solve, and designed a prototype solution that demonstrated the solution's technical and economic viability. Students also generated and submitted case studies that captured both of the problems they identified, and these remain available for both the host organization and our university for learning purposes. A preliminary assessment of the case studies provided evidence that students had applied need analysis methods at a more advanced level than other students in their cohort who did not participate in the pilot.

Bata Colombia worked closely with the students and partnered to find solutions to the problems identified. The company supported the student findings and Bata was impressed with the methodology and the quality of the students' work. Bata will initiate many of the recommendations the students provided, which is a validation of the project.

If Bata were to organize a second iCapstone co-op implementation at another one of its factories worldwide, it would work to more effectively involve factory management from the start, including in the selection of the students, goal setting and the identification of problem areas. This would allow the factory managers to be involved on an individual basis, which would make the program even more successful. Similar to the monitoring group from Canada, a focus group from the factory would form a vital link to ensure the success of the project.

In the follow up survey and focus group discussion, the students stated that they perceived their learning during their iCapstone co-op term to be practical, useful and delivered in a timely way. They reported 
that they learned more since you are able to constantly and actively apply learned concepts when the opportunities are 'right in front of you'.

Virtual instruction was effective in being able to deliver the educational content, and to facilitate the learning of engaging with the problems they identified. The use of shared screens and a whiteboard over the virtual connection was almost as effective as meeting in person.

From an educator's perspective, the experience seemed very much like the studio-like teaching experience with students during a regular capstone course on campus. The technology was relatively reliable and we were able to share slides and sketches in real time.

Students, as novice professionals, generally underestimate the importance and impact of non-technical elements of an engineering activity, such as communication, project/risk management, and cultural aspects. It is likely that they expected more technical focus and less non-technical focus, however, they faced a truly authentic professional practice situation - messy indeterminant situations, that forced them to engage fully with an authentic practice environment, unshielded from management, and not in an academic, science-based environment.

In this sense, the pilot achieved its purpose and more.

\section{Acknowledgement}

The authors would like to acknowledge the support of University of Waterloo Cooperative Education, specifically our executive sponsor, Dr. Rocco Fondacaro, engineering faculty relations manager Mr. Philippe Bezaire, Coop 2.0 project manager Mrs. Peggy Eichenger, and director for the Centre for Advancement of Cooperative Education, Ms. Judene Pretti, for their outstanding support of this first pilot implementation. The authors gratefully acknowledge your vision and support of this new programming.

The authors also acknowledge Waterloo Centre for the Advancement of Co-operative Education (WatCACE) for funding through the Learning Innovation and Teaching Enhancement (LITE) grant process.

\section{References}

Bucciarelli, L.L. (2003), "Designing and learning: A disjunction in contexts", Design Studies, Vol. 24 No. 3, pp. 295-311. https://doi.org/10.1016/s0142-694x(02)00057-1

Buhkman, I. (2012), TRIZ Technology for Innovation, Cubic Creativity Company, Taipei.

Cardoso, C., Eris, O. and Badke-Schaub, P. (2014), "Question-Asking in Design Reviews: How Does Inquiry Facilitate the Learning Interaction”, Design Thinking Research Symposium 2014, Purdue University.

Christensen, C.M. and Eyring, H.J. (2011), The Innovative University: Changing the DNA of Higher Education from the Inside Out, John Wiley \& Sons.

Dyer, J., Gregersen, H. and Christensen, C.J. (2011), The Innovator's DNA: Mastering the Five Skills of Disruptive Innovators, Harvard Business Press.

Eris, O. (2004), Effective Inquiry for Innovative Engineering Design, Spinger-Science + Business Media, New York. https://doi.org/10.1007/978-1-4419-8934-7

Gero, J. and Kannengiesser, U. (2003), "The situated function-behavior-structure framework", Design Studies, Vol 25 No. 4, pp. 373-391. https://doi.org/10.1016/j.destud.2003.10.010

Henderson, J.V. (1998), "Comprehensive, technology-based clinical education: The virtual clinical practicum", International Journal of Psychiatry in Medicine, Vol. 28 No. 1, pp. 41-79. https://doi.org/10.2190/nqen-krt819ga-r0bv

Hurst, A. and Nespoli O.G., (2018), A Comparison of Instructor and Student Verbal Feedback in Engineering Capstone Design Review Meetings: Difference in Topic and Function (Working paper). [online] University of Waterloo, Ontario. Available at:

https://uwaterloo.ca/scholar/sites/ca.scholar/files/adahurst/files/hurst_nespoli_2018_comparison_of_instructo r_student_feedback.pdf

Jonassen, D.H. (2000), "Toward a design theory of problem solving", Educational Technology Research and Development, Vol. 48 No. 4, pp. 63-85. https://doi.org/10.1007/bf02300500

Nespoli, O.G. and Russell, J. (2016), "iCapstone - A novel academic program that integrates cooperative education and interdisciplinary capstone design to deepen interdisciplinary design learning", Proceedings of the Design Management Institute (DMI) Academic Conference, Boston, July 28-29, 2016.

Schon, D.A. (1987), Educating the Reflective Practitioner: Toward a New Design for Teaching and Learning in the Profession, Jossey-Bass, San Francisco. 


\section{Appendix}

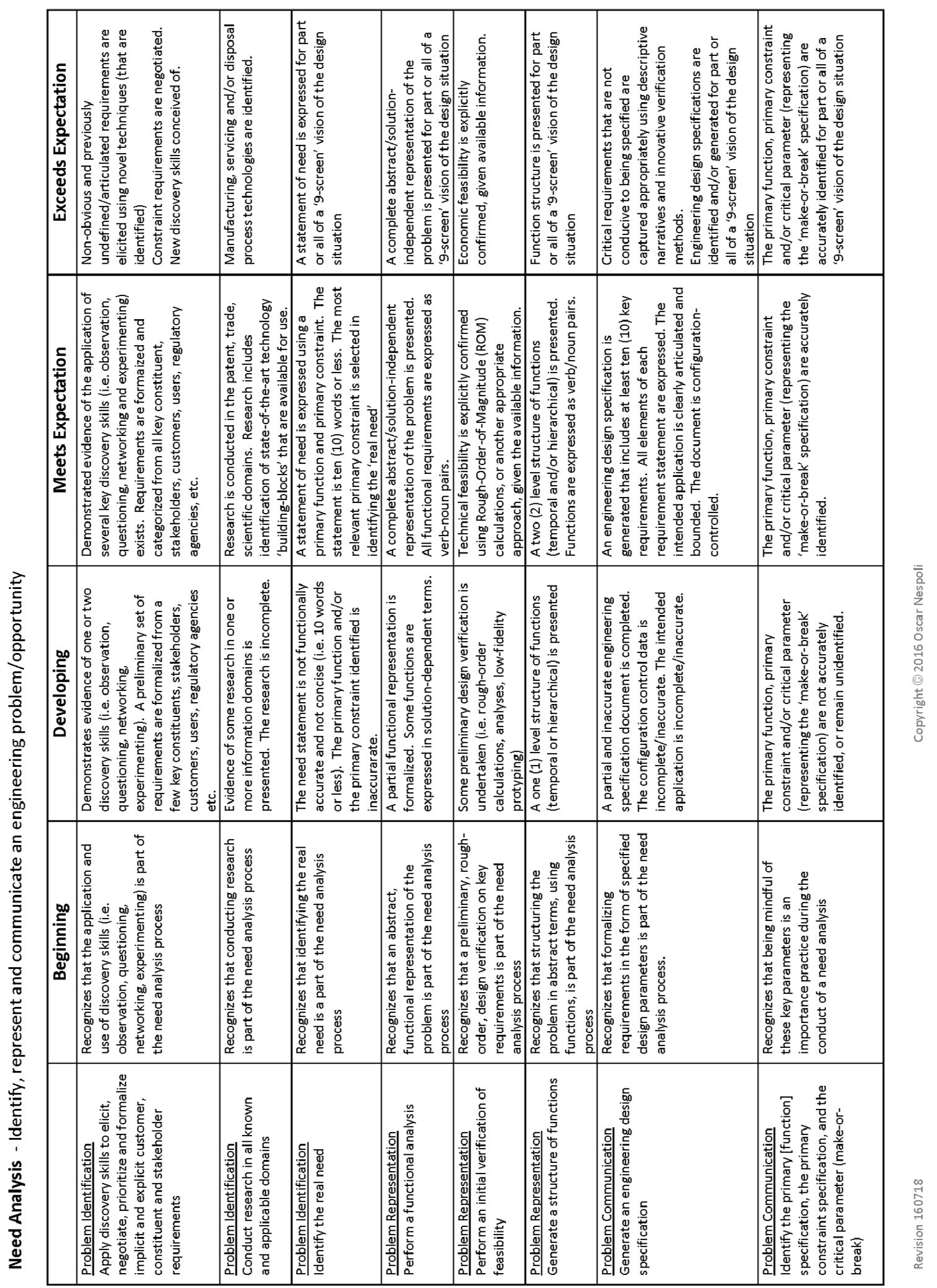


Prof. Oscar Nespoli, Continuing Lecturer University of Waterloo

59 Pine Ridge Drive, N1L 1J3 Guelph, Canada

Email: oscar@uwaterloo.ca 